\title{
ANALISIS DESAIN OPTIMUM SPROKET RODA BELAKANG SEPEDA MOTOR DENGAN BENTUK LENGAN SPROKET LURUS KRITERIA BIAYA MATERIAL MINIMUM
}

\author{
Insana Jatmiko ${ }^{1}$ \\ Program Setudi Teknik Mesin, Universitas Pamulang \\ Jl. Surya Kencana No.1 Pamulang, Tangerang Selatan, Banten, Indonesia \\ Email : dosen01950@unpam.ac.id \\ Dajukan 15 Maret $2018 \quad$ Direvisi : 29 Maret $2018 \quad$ Disetujui : 6 April 2018
}

\begin{abstract}
Abstrak: Pertumbuhan jumlah sepeda motor dalam negri sangat signifikan karena jumlah penduduk yang banyak dan ekonomi yang stabil. Hal ini mendorong peningkatan pembuatan komponen-komponen sepeda motor oleh perusahaan kecil. Peningkatan tersebut harus dibarengi dengan peningkatan daya saing produk. Usaha yang dilakukan diantaranya dengan melakukan optimasi desain produk kriteria biaya material minimum. Sproket dalam negri perlu dilakukan optimasi agar lebih kompetitif dengan cara memilih material yang mampu menjalankan fungsinya dan harga kebutuhan material minimum dengan menggunakan Metode Desain Optimum Kriteria Biaya Kebutuhan Material Minimum. Material yang diseleksi yaitu material yang pada umumnya dipakai oleh industri dalam negri: S45C, AISI 1045, AISI 5140, GG25, dan 20MnCr5. Umur sproket yang diharapkan lebih dari 3 tahun ( $\pm 3,7$ x 107 siklus). Hasil analisis menunjukan baja S45C paling optimum untuk membuat sproket.
\end{abstract}

Kata kunci: sproket, seleksi material, desain

Abstract: The number of motors cycle is increasing significantly because of the number of people and stabilized economic. This case supports motors cycle manufacturing for small companies. It should be joined by the increasing of power competition. One of the efforts is by optimizing product in minimum category. Local sprocket should be optimized so that more competitive. The selection of rear wheel sprocket materials is to get a material which is good in function and competitive cost. The material selection is commonly used materials in local industries such as S45C, AISI 1045, AISI 5140, GG25 and 20MnCr5. The analysis is based on The Optimum Design Method for Minimum Material Cost. The result is $\mathrm{S} 45 \mathrm{C}$ as the optimum material

Keywords: sprocket, material selection, optimum design

\section{PENDAHULUAN}

Laju produksi sepeda motor di Indonesia yang tinggi mendorong peningkatan pembuatan komponenkomponen sepeda motor oleh industri dalam negri. Peningkatan tersebut harus diiringi dengan peningkatan daya saing produk sehingga mampu bersaing di pasar global. Usaha yang dapat dilakukan diantaranya dengan melakukan optimasi desain produk kriteria biaya material minimum.

Salah satu komponen utama sepeda motor yang diproduksi oleh industri dalam negri yaitu sproket. Agar sproket tersebut mampu bersaing di pasar global maka perlu dioptimasi sehingga diperoleh sproket yang terpenuhi prasyarat fungsinya dengan biaya material minimum. Metode yang digunakan disini yaitu Metode Desain Optimum Kriteria Biaya Kebutuhan Material Minimum. Dengan metode ini dapat memilih material yang dapat menjalankan fungsinya dan biaya kebutuhan materialnya minimum. [1]

Dalam metode desain optimum, Persamaan Desain Umum Final terdiri dari kelompok parameter fungsi, geometri dan material. Dengan memasukan parameter material: tegangan yield, massa jenis, poison rasio, modulus elastisitas dan harga/masa, dan dengan membuat parameter fungsi dan geometri konstan maka akan diperoleh Biaya Material Minimum dari material-material yang dianalisis. [1] 


\section{METODOLOGI}

Penelitian ini akan membahas bagaimana cara memilih material sproket sepeda motor yang optimum. Sproket yang dianalisis yaitu sproket dengan gigi 36 dengan bentuk arm melengkung. Sproket jenis ini biasa digunakan pada motor (105-150) cc. Momen torsi motor berkisar (130-220) N.m [2][3]. Material sproket yang diteliti yaitu material yang pada umumnya digunakan diantaranya: S45C, AISI 1045, AISI 5140, GG25, dan 20MnCr5.[4]

Gambar sproket yang dianalisis beserta parameter geometrinya yaitu

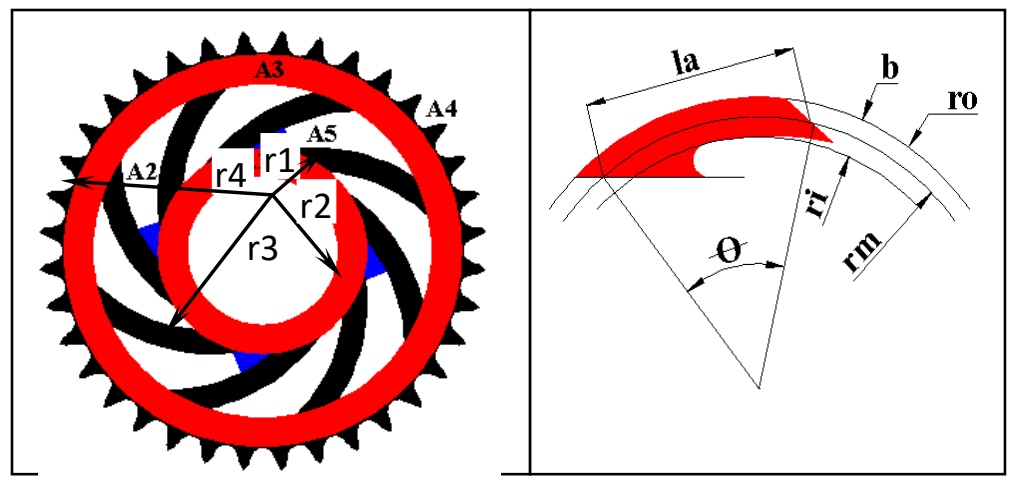

Gambar 1 Sproket yang dianalisis [2],[5]

Metode untuk memilih material yaitu dengan menurunkan rumus biaya kebutuhan material per sproket sebagai fungsi dari kelompok parameter: fungsi, geometri dan material. Rumus biaya kebutuhan material: $\mathrm{Cm}=$ c.w.t.A. Dimana c: harga per berat; w: berat; t: tebal dan A luas sproket. Variabel c dan w merupakan variabel tetap/terikat oleh jenis materialnya.

A dan $t$ merupakan variabel bebas yang dirumuskan lebih lanjut. A fungsi dari variabel bebas r2, r3, b1, b2 dan b3 sedangkan, r4, r1, rm, la, dan $\phi$ dijadikan variabel tetap yang terikat oleh desain. Variabel bebas b1, b2, b3 dan t diturunkan terlebih dahulu sehingga merupakan fungsi dari parameter material [6].

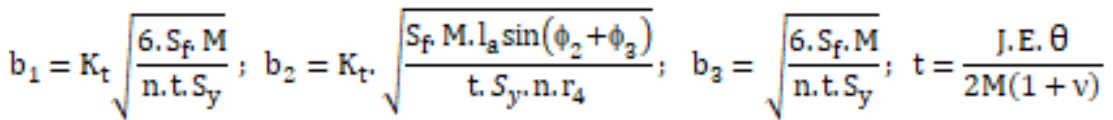

Dimana:

Kt: Faktor konsentrasi tegangan; Sf: faktor keamanan; Mt: momen torsi; n:jumlah lengan; Sy: tegangan mulur; E: modulus Elastisitas; J: momen inersia polar; $\theta$ : sudut puntir; v: rasio poisson.

Rumus luas tiap bagian sproket:

$$
\begin{aligned}
& \text { hub: } A_{1}=\pi b_{1}\left(b_{1}+2 r_{1}\right) \text { : lengan: } A_{2}=b_{2} r_{m} \emptyset_{1} \text { rim: } A_{a}=\pi b_{a}\left(2 r_{4}-b_{a}\right) \\
& \text { luas sproket: } A=A_{1}+A_{2}+A_{a}+A_{4}=\pi\left(b_{1}{ }^{2}-b_{a}{ }^{2}\right)+2 \pi\left(b_{a} r_{4}+b_{1} r_{1}\right)+n b_{2} r_{m} \emptyset_{1}+N_{g} A_{g}
\end{aligned}
$$

Pengembangan dari rumus Biaya Material menjadi

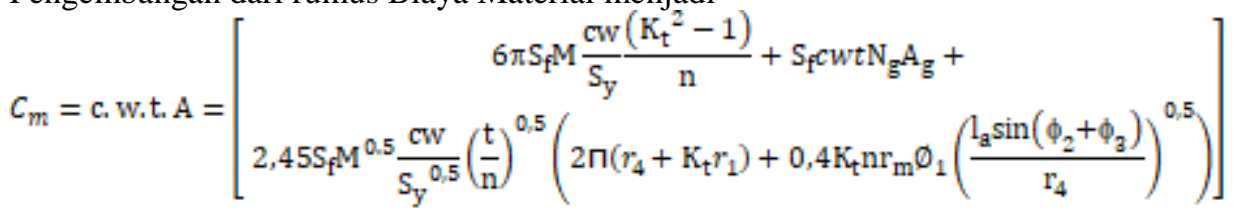

karena parameter geometri dan fungsi dibuat kostan sedangkan parameter material sebagai variabel bebas maka menjadi

$$
\mathrm{C}_{\mathrm{m}}=\mathrm{K}_{1} \frac{\mathrm{S}_{\mathrm{f}} \mathrm{Cw}}{\mathrm{S}_{\mathrm{y}}}+\mathrm{K}_{2} \frac{\mathrm{S}_{\mathrm{f}} \mathrm{cwE}}{1+\mathrm{v}}+\mathrm{K}_{\mathrm{a}} \frac{\mathrm{S}_{\mathrm{f}} \mathrm{CwFE}^{0,5}}{\left(\mathrm{~S}_{y}(1+\mathrm{v})\right)^{0,5}}
$$

$\mathrm{K} 1$, K2 dan K3 adalah konstanta kelompok parameter geometri dan fungsi. Dengan memasukan rumus faktor keamanan yaitu [7] 
Dimana:

St: kekuatan material terhadap gesekan; YN: Faktor kekuatan material terhadap gaya tekan/abrasi relatif terhadap putaran. KT: Faktor kekuatan material relatif terhadap kenaikan suhu. KR: Faktor kekuatan material terhadap proses pengerjaaan halus/kasar

Maka Faktor Seleksi Material seproket.

$$
\text { FSM }=\operatorname{cw} \sqrt{\frac{\mathrm{Y}_{\mathrm{N}} \mathrm{S}_{\mathrm{t}} \mathrm{E}}{\mathrm{S}_{\mathrm{y}} \mathrm{K}_{\mathrm{T}} \mathrm{K}_{\mathrm{R}}(1+\mathrm{v})}} \cdot 10^{-9}
$$

Persamaan Cm diuji kesetaraannya dengan analisis dimensi

$$
\begin{aligned}
& \text { Suku ke-1: }[\mathrm{I}]=\frac{[\mathrm{M}][\mathrm{L}]^{2}[\mathrm{~s}]^{-2} \times[\mathrm{M}]^{-1}[\mathrm{~L}]^{-1}[\mathrm{~s}]^{2} \times[\mathrm{M}][\mathrm{L}]^{-2}[\mathrm{~s}]^{-2}}{[\mathrm{M}][\mathrm{L}]^{-1}[\mathrm{~s}]^{-2}}=[\mathrm{l},(\text { setara }) \\
& \text { Suku ke-2: [ ] }=\frac{[\mathrm{M}][\mathrm{L}]^{-1}[\mathrm{~s}]^{-2} \times[\mathrm{M}]^{-1}[\mathrm{~L}]^{-1}[\mathrm{~s}]^{2} \times[\mathrm{M}][\mathrm{L}]^{-2}[\mathrm{~s}]^{-2}[\mathrm{~L}]^{2}[\mathrm{~L}]^{4}}{[\mathrm{M}][\mathrm{L}]^{2}[\mathrm{~s}]^{-2}}=[],(\text { setara) } \\
& \text { Suku ke-3: }[\mathrm{L}]=\frac{[\mathrm{M}][\mathrm{L}]^{2}[\mathrm{~s}]^{-2} \times[\mathrm{M}]^{-1}[\mathrm{~L}]^{-1}[\mathrm{~s}]^{2} \times[\mathrm{M}][\mathrm{L}]^{-2}[\mathrm{~s}]^{-2}}{[\mathrm{M}][\mathrm{L}]^{-1}[\mathrm{~S}]^{-2}}=[],(\text { setara })
\end{aligned}
$$

Agar satuan di ruas kiri sama dengan satuan diruas kanan maka dihitung Faktor Konversi Satuan

$$
\begin{aligned}
& \text { Suku ke }-1 \mathrm{~s} \$=\frac{\mathrm{Nmm} \cdot \$ \mathrm{~N}^{-1} \times \mathrm{Nm}^{-\mathrm{d}}}{\mathrm{Nmm}^{-2}}=\$ .10^{-9}
\end{aligned}
$$

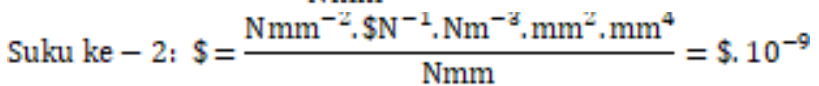

$$
\begin{aligned}
& \text { Suku ke-3:\$ }=\frac{\$ \mathrm{~N}^{-1}{ }_{\mathrm{x}} \mathrm{Nm}^{-8}\left(\mathrm{Nmm}^{-2}\right)^{0.5}{ }^{2}\left(\mathrm{~mm}^{4}\right)^{0.5}{ }_{x \mathrm{~mm}}}{\left(\mathrm{Nmm}^{-2}\right)^{0.5}}=\$ .10^{-9}
\end{aligned}
$$

Persamaan satara dan faktor konversi satuan $10^{-9}$

\section{HASIL DAN PEMBAHASAN}

Hasil penelitian berupa nilai dari faktor seleksi material yang menunjukan tingkat keoptimuman dari material yang dianalisis untuk umur 3 tahun( \pm 3,7 x 107 siklus) Agar Nilai Faktor seleksi Material diperoleh maka data-data material yaitu c, w, Sy, w, E, v, St, YN, KR, dan KT di masukan ke dalam persamaan 5. Keakuratan data sangat berpengaruh terhadap tingkat validasi Nilai Faktor Seleksi Material. Faktor ketahanan

\begin{tabular}{|c|c|c|c|c|c|c|}
\hline $\begin{array}{r}\text { Sifat } \\
\text { Material }\end{array}$ & $\mathrm{S} 45 \mathrm{C}$ & $\begin{array}{l}\text { AIS } \\
\text { I } 1045 \\
\end{array}$ & $\begin{array}{r}\text { AIS } \\
\text { I } 5140 \\
\end{array}$ & $\begin{aligned} \text { DIN } \\
\text { GG25 }\end{aligned}$ & $\begin{array}{l}20 \mathrm{Mn} \\
\mathrm{Cr} 5\end{array}$ & Satuan \\
\hline Sy & 418 & 420 & 383 & 190 & 578 & $\mathrm{~N} / \mathrm{mm} 2$ \\
\hline $\mathrm{W}$ & 7865 & $20 \begin{array}{ll} & 787 \\
20 & \end{array}$ & $20 \quad 767$ & 7200 & 7810 & $\mathrm{~N} / \mathrm{m} 3$ \\
\hline $\mathrm{E}$ & $\begin{array}{ll} & 2000 \\
00 & \end{array}$ & $000^{201}$ & $000^{205}$ & $\begin{array}{ll} & 1150\end{array}$ & 2100 & $\mathrm{~N} / \mathrm{mm} 2$ \\
\hline$v$ & 0,27 & 0,27 & 0,27 & 0,26 & 0,27 & \\
\hline $\mathrm{c}$ & 8,3 & 11,3 & 15,0 & 11,5 & 20,0 & $\$ / N$ \\
\hline $\mathrm{BHN}$ & 220 & 210 & 241 & 240 & 213 & $\mathrm{~N} / \mathrm{mm} 2$ \\
\hline
\end{tabular}
material terhadap tekanan per siklus (YN) untuk baja berdasarkan grafik pada referensi [8] sama 0,99679, sedangkan GG25 (besi cor) lebih kecil 0,96315. Faktor koreksi kekuatan material relatif terhadap suhu KT dan relatif terhadap proses pengerjaaan KR diambil sama untuk semua material.

Tabel-1 Parameter Karakteristik Material dari Lima Jenis Baja yang Dianalisis [6],[7],[8],[9] 
Jurnal Teknik Mesin: CAKRAM (2018)

Insana Jatmiko, Analisis Desain Optimum Sproket...,

\begin{tabular}{|l|ll|l|l|l|l|c|}
\hline St & & 268 & 261 & 282 & 190 & 266 & Nmm-2 \\
\hline YN & \multirow{2}{*}{0,996} & \multicolumn{2}{|c|}{0,99} & 0,99 & 0,963 & 0,996 & - \\
\hline KR & 0,85 & 0,85 & 0,85 & 0,85 & 0,85 & - \\
\hline KT & 1 & 1 & 1 & 1 & 1 & - \\
\hline
\end{tabular}

Data pada tabel-1 di atas dimasukan kedalam rumus persamaan-5 seperti d ibawah ini, kemudian diperoleh hasilnya pada Tabel-2

$$
\text { FSM }=c w \sqrt{\frac{\mathrm{Y}_{\mathrm{N}} \mathrm{S}_{\mathrm{t}} \mathrm{E}}{\mathrm{S}_{\mathrm{y}} \mathrm{K}_{\mathrm{T}} \mathrm{K}_{\mathrm{R}}(1+v)}} \times 10^{-\mathrm{g}}
$$

Tabel-2 Nilai Faktor Seleksi Material dari Material yang Dianalisis

\begin{tabular}{|c|c|c|c|c|c|c|}
\hline $\begin{array}{ll} & \text { FS } \\
\text { M } & \\
\end{array}$ & $221 \quad 0,00$ & $47 \quad 0,003$ & $26 \quad 0,004$ & $85 \quad 0,002$ & $62 \quad 0,004$ & $\begin{array}{l}\text { \$N0,5 } \\
\text { mm-4 }\end{array}$ \\
\hline $\begin{array}{ll} & \mathrm{N} \\
\mathrm{o} & \end{array}$ & 1 & 3 & 4 & 2 & 5 & \\
\hline
\end{tabular}

Nilai faktor seleksi material yang paling kecil baja S45C, yaitu 0,00221 \$N0,5mm-4 . Nilai ini menunjukan bahwa S45C paling optimal artinya terpenuhinya semua parameter prasyarat fungsi dan material. Dilihat dari satuanya menunjukan faktor seleksi material merupakan fungsi dari harga, gaya yang bekerja pada sproket, dan ukurannya. sehingga mampu bertahan sampai 3 tahun (3,6 x 107 siklus) dan kemudian berturutturut: GG25, AISI 1045, AISI 5140 dan 20MnCr5.

\section{KESIMPULAN}

Material yang paling optimal untuk membuat sproket roda belakang sepeda motor dengan spesifikasi geometri sebagaimana di atas, dengan batasan momen torsi yang bekerja pada sproket $130 \mathrm{Nm}-220 \mathrm{Nm}$, dari lima material alternatif yang biasanya digunakan sebagai bahan sproket, S45C merupakan material yang paling optimal, sehingga menjadi material yang disarankan penulis.

\section{DAFTAR PUSTAKA}

[1]. Karmiadji, D. W., 2011. Optimasi Desain (Material, Komponen, Konstruks) Teori Dasar dan Aplikasi. Engineering Clinics FTUP, Jakarta.

[2]. Spsifikasi Sproket gigi 36, Indopart, 2010

[3]. Spesifikasi Sepeda Motor Supra-X, Honda, 2010

[4]. American Chain Association Chains for Power Transmission and Material Handling, 2005. The American

Chain Association Chains for Power Transmission and Material Handling handbook. USA.

[5]. Arifin, Lukman, 2005. Belajar AutoCAD 2000. Erlangga

[6]. Khurmi, J. R. (2004). A Textbook of Machine Design (13th edition). New Delhi: Mc. Graw-Hill Companies, Inc.,

[7]. Nisbett, Budynas, 2008. Mechanical Engineering Design. The McGraw-Hill Companies, Inc

[8]. Internet WWW. Daftar Harga Baja.com

[9]. Bringas, Jhon E, 1953. Handbook of Comparative World Steel Standards (3th edition), ASTM 